\title{
Touring space science: the HABIT Tour experience
}

\author{
José Antonio Gordillo Martorell \\ Group of Atmospheric Science (GAS) \\ Division of Space Technology, Department of Computer \\ Science, Electrical and Space Engineering, Luleå Tekniska \\ universitet \\ Luleå, Sweden \\ jose.antonio.gordillo.martorell@1tu.se
}

\author{
Javier Martin-Torres \\ Group of Atmospheric Science (GAS) Division \\ of Space Technology, Department of Computer \\ Science, Electrical and Space Engineering, Luleå \\ Tekniska universitet Luleå, Sweden \\ javier.martin-torres@ltu.se
}

\author{
María-Paz Zorzano \\ Group of Atmospheric Science (GAS) \\ Division of Space Technology, Department of Computer \\ Science, Electrical and Space Engineering, Luleå \\ Tekniska universitet \\ Luleå, Sweden \\ Centro de Astrobiología (CSIC-INTA) \\ Madrid, Spain \\ maria-paz.zorzano.mier@ltu.se
}

The HABIT Tour is one of the activities within the strategic activity of GAS to communicate science: a science communication experience that propose a new way to engage people with space science and technology. The HABIT Tour is an itinerant innovative low-cost outreach exhibition to engage society in in situ different kind of audiences. With this activity, we try to build a face to face and a digital community around a space instrument whose one of the main goals is to produce liquid water on Mars within the ExoMars 2020 mission. In this paper we explain some of the mains challenges, opportunities and results of the experience that can be useful for future space engagement and learning activities.

Keywords-HABIT; ExoMars 2020 mission; Open Space Science; learning co-creation; Habitability, life, water, Planetary Protection, space technology.

\section{A SPACE INSTRUMENT AS A SCIENCE TOUR}

Since March 2018 the Group of Atmospheric Science (GAS) [1] of Luleå University of Technology [2] is developing a new science communication strategy based on an itinerant innovative low-cost outreach exhibition, with the presence of researchers, that allows the direct contact between researchers and audience. The key point of the strategy is to create the conditions for a reciprocal benefit. From one side the experience should help the researchers to evaluate their capability to reach successfully different audiences; and can provide the possibility to audiences to interact directly with researchers and change their perception about the social role and relevance of researchers. Moreover the experience can help audiences to think in terms of logics, and how to use and apply scientific methodology in their everyday-life, how to analyse, verify information, classify, relate, and evaluate the world around.
The strategy integrates some key points: a personal researcher involvement, a research project to be shared, an audience research centered and a feedback to the researchers. The strategy is adapted to different kind of audiences, such as children, young people, families, journalists, digital audiences and influencers, groups with special needs or artists. The strategy permits different approaches to achieve different goals as improve science and technology vocations in young people, facilitate the dialogue between researchers and companies, cooperate and support institutional changes to give researchers efficient incentives to communicate science, design new research policies, or increase the relevance of researchers social role.

One of the possibilities of this strategy is to include early educative levels, as preschool, stimulating children with real (but adapted to their level) science. Some years ago universities all over the world started to interact with high-school students to be more visible and accessible to them. Later on, universities attracted Primary School people with Fun- Fairs, Open Days and "door-to-door" visits. Today universities are expanding their influence and interaction to preschool levels and that is the point where GAS science communication strategy appears. 
Luleå University of Technology (LTU) is a young university placed on the north of Sweden focused on the creation of innovative learning and researching ecosystems and methodologies. One of the strategic areas is the space research and the space prototyping, taking advantage of the presence of fundamental space infrastructures as the European Space and Sounding Rocket Range Space Center (ESRANGE), business incubators as LTU Business AB, specific space educational university training in Kiruna and Luleå Campuses, or high school training in the Rymdgymnasiet in Kiruna, a space curriculum centered high school.

GAS is a LTU research group focused on the study of Earth and planetary atmospheres and the development of instruments for Earth and planetary exploration: from idea to instrument design, development, calibration, operations and data analysis. GAS is a worldwide repute cutting-edge planetary research group with articles in high-impact hournals as Nature, Science, PNAS... The senior members of GAS provide assessment to international space organizations: ESA, JAXA, NASA, EUA and are members of ESA, NASA, ERC panels. GAS has a very relevant role in Educational programs in Space with the largest number of participants in ESA Academy programs of all Universities in Europe in 2017.

The HABIT (HAbitability: Brines, Irradiation and Temperature) instrument [3] proposed by Prof. Martin-Torres and Prof. Zorzano from the GAS was selected by the European Space Agency to be one of the two European instruments on board the ExoMars' Surface Platform (the Russian contribution to the mission). The Flight-Model of HABIT was delivered to the ESA Office in Moscow in July 2019. The main scientific goals of the instrument are:

1. To provide environmental information at the Landing Site.

2. To demonstrate liquid water formation on Mars.

3. To test an In-Situ Resource Utilization technology for future Mars exploration.

HABIT will contribute to one of the main goals of the ExoMars Program [4]: "to search for signs of past and present life on Mars". It will open ways to start planning future manned missions to Mars by serving as a first step in the development of the technology to produce liquid water on Mars, one of the main resources which a prospective crew will need to explore the planet.

Usually space technology, and all the science around it, is seen as a "black box" by society. It is something distant, maybe interesting but incomprehensible, strange, difficult to understand, something done by experts only for experts, something that you can see on TV or internet only as mere spectator without no chances to meet, to touch, to use as a learning tool to be meaningful in everyday life people.
The HABIT Tour [6] is one of the activities within the strategic activity of GAS to communicate science: a science communication experience that propose a new way to engage people with space science and technology (S\&T). The As if HABIT were a "Rock'n Roll Star", our HABIT exhibition is showing off around Sweden, home of LTU. The HABIT Tour tries to "break" this S\&T people's perception in Sweden, developing a very special way to share cutting-edge space knowledge with different kind of audiences such as university and high school students, families, children, journalists, space fans, maker communities, companies etc... Our purpose is to build a national proud on science activities like HABIT, that will be first ever Swedish science instrument to land on Mars [5].

\section{OPENING THE SPACE SCIENCE BLACK BOX}

\section{A. A three steps methodology to start the conversation with the audience}

We have followed a series of steps to be visible and engage our target audiences with our open content:

- Step1: The space technology goes out the laboratory and looks for the audience. That's the touring approach. We transform the space technology in a character that "visits" the country as a music star does in a concert.

- Step 2: People start a conversation with the space technology, a dialogue. They can touch it, use it to learn science in family, class, at home etc..., they can create their own HABIT instrument customizing it, creating it, developing new applications, relating it in different ways with their everyday life. It is the Hands-On and Do It Yourself approach, opening the technology to all the audiences to emulate and reproduce it using 3D printers, software and open technology in general etc.

- Step 3: People create a HABIT Community in schools, universities, science and culture centers, fab labs, maker spaces, airports, libraries, or at home using HABIT for things completely different as it has been planned. HABIT is relevant in their everyday life to do something unexpected and they share it with other audiences and with us giving creative feedback and engagement. The HABIT instrument is something meaningful and interesting in their everyday life that can be used to learn, research, create or make friends. In this stage the long journey from the laboratory has finished. But also starts the most exciting part based on the audience's feedback.

\section{B. Goals and associated indicators to measure the audience impact and engagement}

The HABIT Tour is part of the broader GAS Open Science strategy. Is a good example of an "expertise science" transformed in "science for all". The main goals of the HABIT Tour are "under the umbrella" of the general GAS communication strategic goals. 
Each one of the specific goals has their specific indicator to measure the level of achievement reached:

- To transform a "black box" space instrument in a science national icon. Indicator: Media and social media impact.

- To develop a low-cost (about 6.000 €) outreach resource very easy to move, to install/uninstall and to adapt to different kind of audiences with different interests and backgrounds. Indicator: Budget and different kind of audiences involved.

- To create and share an interesting and inspiring story related with space discovery and exploration. Indicator: number of educative guides and workshop materials downloaded.

- To share HABIT and space research as a knowledge experience open to audience's curiosity and creativity. Indicator: number of 3D Prints prototypes created.

- To improve scientific and technological vocations in children and young people. Indicator: number of high school students registered in LTU.

- To create an increasing social expectation and interest about the instrument until July 2020 (date of mission launching- the launch will be broadcasted live in Luleå). Indicator: number of people up-to-date with HABIT.

\section{ON TOUR}

The HABIT Tour is conceived as a simple and friendly outreach resource that goes out to meet people to provoke them an experience of curiosity and passion improvement about Mars. In that sense is a flipped outreach tool but a very flexible tool too.

When we designed the first edition of the Tour we kept in mind all this, and included in the planning the specific target audiences: children and teenagers, educators, makers, science fiction fans, university space engineers, curious families and curious minds in general. First, the target audience was defined, and then that constrained the place of the activity, in order to find them.

In the first edition the HABIT Tour is visiting ten different locations inside and outside Sweden. The locations were chosen following the next criteria:

- Target audience presence.

- Science engagement profile (especially in space arena).

- Prestige and background.

- Media and social media impact.

- Networking.

- Combination of classical and more innovative outreach and learning institution profiles.

The HABIT Tour first edition - from November $14^{\text {th }} 2018$ to

November $14^{\text {th }} 2019$ - is shaped by ten different locations:

· Luleå tekniska universitet.
- Umeå University. Umevatoriet (a Science Center).

- The SciFest of Uppsala University.

- The Space week of KTH Space Center.

- The International Science Festival in Gothenburg.

- The Malmö University.

· Luleå Hamnfestival.

- Luleå Airport.

- National Space Center. Leicester UK.

- New Scientist Live Festival. London.

· Luleå Kulturens Hus.

The second HABIT Tour edition -from November 15th 2019 to July 2020 - will be hosted in:

- Ice Hotel. Jukkasjarvi, Sweden.

Rymdgymnasiet Kiruna, Sweden.

- New Scientist Live North. Manchester. UK

- Lindholmen Science Park, Sweden.

- The International Science Festival in Gothenburg

- Innovatum Science Center, Sweden.

- University of Lund, Sweden.

- Experimentarium. Denmark

- Luleå Hamnfestival (launching broadcast event).

The agreement with all the partners who are interested in HABIT includes the acceptance of the cost of shipping from the previous place, the installation/uninstallation, media and social media coverage and the preparation of a results report at the end of the stay. We provide the partners with all the materials (including a mediator guide, a set of educative guides in Swedish/English for two levels, 7-11 years old and 816 years old, a workshop materials and a 3D Print HABIT Model guide), some training for the people in charge and the schedule management.

The HABIT Tour content is a tailor-made box which contains several resources to interact with the audience:

- A set of roll-ups with big size Mars images and some representative text like "Water on Mars".

- A screen with a short video explaining the making off of the instrument by the researcher on charge, Chair Professor Javier Martin-Torres.

- A display with a challenge for the audience, a quiz with three representative objects they can relate among themselves: a salt dehumidifier (which reproduces in some way the same "water capture" mechanism of the salts in the HABIT vessels), an exact replica of the instrument and a greenhouse mockup (as an example of future potential in situ uses of the hydrogen and oxygen on Mars). This last resource was made by 
kindergarten five years old children imaging how will be the life of plants, trees and insects on Mars.

The installation includes a couple of QR Codes to download a survey for educators and general audience feedback. It can be installed and uninstalled in 10 minutes.

The HABIT Tour can be used in two different ways: - As an autonomous small exhibition that can be visited in 15 minutes.

- As a scenario to interact with the audiences in a non-stop way or in a programed way with workshops, hands-on laboratory experiences, sessions of storytelling and gamification for

children and families etc...

\section{SOME RESULTS AND CONCLUSSIONS}

\section{A. Quantitative results}

From the opening of HABIT Tour (November 14, 2018)

until July $1^{\text {st }} 2019$ the main quantitative results are:

- Number of engaged people: 43.245 people (including children, teenagers, university students, educators, journalists, space researchers, science communicators, families, makers, astronomy associations and open technology fans).

- Number of digital educative resources downloaded from the HABIT Tour website: 281.

- Number of active HABIT Tour followers in social media: 51

- Number of workshops done: 7.

- Number of Spin-off projects - do your own HABIT model to improve it in some way-: 6 (one from a ten years old children, 2 from high school students of Stockholm related to architecture on Mars and 2 from high school teachers).

\section{B. Qualitative results}

Beyond the numbers we have tried to create in the different audiences a specific experience. The main aim was to improve their curiosity about exploration, discovery and experimentation using the space technology.

We use the results obtained in the surveys to evaluate the impact of the initiative are pretty positive although there are some fields to improve.

The survey measured the experience with 22 different items related to the content, the people in charge to attend the installation, the communication, the organization and the global experience. The respondent can choose values from 1 (inadequate) to 5 (very good).

- Contents

- The content has been relevant, interesting and inspiring to me.

- I have learnt some important science concepts.

- I have changed my previous conception about the topic.
- $\quad$ After the activity I will continue researching by myself about the topic.

- I will apply the content in my everyday life.

- People

- The communication skills have been good.

- The scientific competence was good.

- The people of the activity has been able to engage me from the beginning

- They open my point of view and my curiosity about the topic

- $\quad$ They use the appropriate language

Organization

- Previous information about the activity has been appropriate.

- $\quad$ The timing has been correct.

- The length of the activity has been correct.

- The resources and materials used has been useful.

- The manners have been fine and friendly.

- The space and light have been comfortable and adequate.

- Final evaluation

- The global experience has been positive.

- I will recommend it to my family, friends, colleagues.

- If it will be possible will repeat the activity.

- I would like to engage with the organization as science volunteer.

- Besides the topic of the activity and inside space, environment and technology field I like very much.

- Give us some ideas to do next time a better activity.

We collected a total of 23 surveys. In all of them they chosen the values 4 and 5 to mark in 17 parameters.

The items with marks bellow 4 have been: application of the content to the everyday life, the volunteer engagement effect and the change of their previous idea about the topic.

Some examples of positive impacts of the HABIT Tour are:

- Children and families who interacted in SciFest in Uppsala moved to Stockholm to continue the dialogue.

- Astronomy amateurs who were part in a Lysvik Värmland Star Party on March $9^{\text {th }} 2019$ came to Goteborg Science Festival to invite us to do the workshop to other Astronomy Association in the city.

The networking has been one of the main outputs of the experience.

\section{Conclusions}

- HABIT Tour is a good tested example of low-cost outreach resource with an efficient and balanced ratio between resources invested and impact achieved. In a flipped approach the content goes out and looks for an active audience interaction. 
- It is very flexible because it can be adapted easily to different kind of audiences with different backgrounds (science capital [7]) and interests using the set of educative materials prepared for learning and fun.

- $\quad$ One of the most valueble aspects of HABIT Tour is its open nature people confirms that they not only can know and understand about the instrument but they can do things with it: creating stories, designing a prototype, starting a educative project, developing a gamer or even a videogame... HABIT goes in the everyday life people's arena to get meaning.

- The importance of the mediator's figure as somebody who is able to start an interesting conversation about Mars habitability with the audience.

- $\quad$ The HABIT Tour is only the first step to build the truly strategic goal that is to build "HABIT communities" involved in space topics.

- $\quad$ The HABIT Tour also inspired in some cases debates about controversial topics as why should be invest so much money in space and not on Earth problems, or some conspiracy theories defenders about our presence on the Moon.

- Interest in space is clearly improved when you look at it from global Earth problems as Climate Change issues.

\section{REFERENCES}

[1] https://atmospheres.research.ltu.se/

[2] https://www.ltu.se/

[3] https://atmospheres.research.ltu.se/habit/

FIGURES

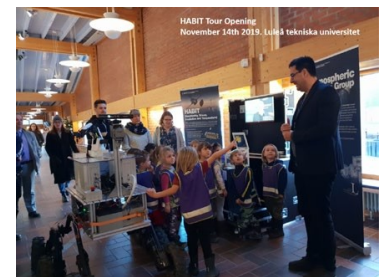

Fig. 1 HABIT Tour Opening in Luleå University of Technology. Credits: GAS.

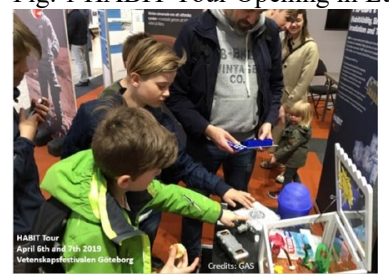

Fig. 2 HABIT Touer in The International Science Festival of Gothenburg. Credits: GAS.

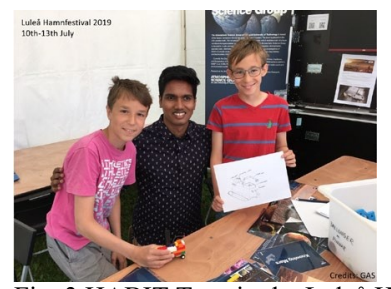

Fig. 3 HABIT Tour in the Luleå Hamsnfestival. Credits: GAS.
[4] https://www.esa.int/Our_Activities/Human_and_Robotic_Exploration/E xploration/ExoMars

[5] http://exploration.esa.int/mars/48088-mission-overview/

[6] https://atmospheres.research.ltu.se/pages/outreach/habittour.php

[7] Archer, Louise \& Dawson, Emily \& DeWitt, Jennifer \& Seakins, Amy \& Wong, Billy. (2015). "Science capital": A conceptual, methodological, and empirical argument for extending bourdieusian notions of capital beyond the arts: SCIENCE CAPITAL. Journal of Research in Science Teaching. 52.10.1002/tea.21227. 